\title{
Toxicity of Salicylic Acid in Cymbidium atropurpureo and Phalaenopsis Golden Peoker Cultivated In Vitro
}

\author{
Cibele Mantovani ${ }^{1}$, Jonas Pereira de Souza Júnior, \\ Renato de Mello Prado, and Kathia Fernandes Lopes Pivetta \\ São Paulo State University (Unesp), School of Agricultural and Veterinary \\ Sciences, Jaboticabal, Path of Access Professor Paulo Donato Castellane, \\ 14884-900 Jaboticabal, Brazil
}

Additional index words. orchid nutrition, Orchidaceae, tissue culture, growth regulator

\begin{abstract}
Salicylic acid (SA) may induce toxicity in orchids depending on its concentration and the plant species, but there is no information about the effect of this substance on orchids cultivated in vitro. The objective of the present study was to evaluate the effects of different concentrations of SA on Cymbidium atropurpureo and Phalaenopsis Golden Peoker cultivated in vitro to verify the biological losses caused by the substance's toxicity. The orchids Cymbidium atropurpureo and Phalaenopsis Golden Peoker were sown in vitro in a Murashige and Skoog (MS)-growth medium and transferred to a medium of the same type containing SA 90 days after sowing. The studied SA concentrations were 0, 50, $100,200,300,400,500$, and $1000 \mu \mathrm{mol} \cdot \mathrm{L}^{-1}$, and the plants were kept in this medium for 210 days. The treatments were distributed into a completely randomized design with four replications. Biometric variables of the seedlings and electrolyte leakage were evaluated 300 days after sowing. The results indicate that the addition of SA interfered with the in vitro growth and development of seedlings of Cymbidium atropurpureo and Phalaenopsis Golden Peoker, given that it caused all the examined variables to show reduced values and triggered electrolyte leakage, consequently inducing toxicity.
\end{abstract}

SA participates in stress signaling pathways, and the exogenous application of this substance may provide protection against biotic and abiotic stresses. The effect of the application of SA depends on several factors, such as the plant species and its development stage, the mode of application and concentration of the substance, and its endogenous level in the plant (Horváth et al., 2007). Studies about the effect of SA on ornamental plants are limited to some species, with exclusive supply via leaf spray, as reported for Stevia rebaudiana (El-Housini et al., 2014) and violets (Martín-Mex et al., 2005).

The in vitro cultivation of orchids has expanded, and the inclusion of SA in the growth medium may enhance their growth, but there is a risk of induced toxicity depending on the species. The description of the effects of SA on orchids is limited to the analysis of the production of polysaccharides by Dendrobium officinale cultivated in vitro (Yuan et al., 2014). According to this study, the exogenous application of SA favored the examined characteristics.

SA-induced toxicity may occur as a consequence of excess production of reactive

Received for publication 15 Oct. 2018. Accepted for publication 5 Dec. 2018.

We express our gratitude to the Brazilian National Council for Scientific and Technological Development for providing the first author with a $\mathrm{PhD}$ scholarship.

${ }^{1}$ Corresponding author. E-mail: orquidariomantovani@ gmail.com. oxygen species, which causes oxidation of cell membrane lipids, resulting in cytosol leakage to the apparent free space (Horvath et al., 2007). This phenomenon leads to losses in plant metabolism and may reflect on growth variables in different ways.

Given this scenario and assuming the hypothesis that orchids cultivated in vitro are sensitive to $\mathrm{SA}$, it is reasonable to assume that supplying this substance in the growth medium may induce toxicity in certain orchid species as a consequence of cellular electrolyte leakage, which impacts on plants' biological variables. Therefore, the present study had the objective to evaluate the effects of different concentrations of SA on Cymbidium atropurpureo and Phalaenopsis Golden Peoker orchids cultivated in vitro to verify the biological losses associated with the substance's toxicity.

\section{Material and Methods}

Closed capsules with mature seeds of the orchids Cymbidium atropurpureo and Phalaenopsis Golden Peoker were superficially disinfected in a $70 \%$ ethanol solution for $5 \mathrm{~min}$ and a $1 \%$ active chlorine solution for $30 \mathrm{~min}$. The capsules were then rinsed three times with distilled and autoclaved water and subsequently opened in a flow chamber. Seeds were inoculated in transparent glass flasks with a volume of $250 \mathrm{~mL}$ containing 40 $\mathrm{mL}$ of MS reduced growth medium and autoclaved at $121{ }^{\circ} \mathrm{C}$ and $1.1 \mathrm{~atm}$ during 15 min (Caldas et al., 1998).
The reduced MS medium has the composition proposed by Murashige and Skoog (1962) with one-half the concentration of macronutrient salts and the full concentration of micronutrients, $2 \%$ of sucrose, gelled with $0.7 \%$ of agar, $\mathrm{pH}$ adjusted to 5.7 , and supplemented with vitamins, inositol, and glycine (Costa et al., 2009). Plant germination and growth occurred in an incubation room with a temperature of $25 \pm 2{ }^{\circ} \mathrm{C}$, an illumination of $\approx 75 \mu \mathrm{mol} \cdot \mathrm{m}^{-2} \cdot \mathrm{s}^{-1}$, and a photoperiod of $16 \mathrm{~h}$ of light.

After $90 \mathrm{~d}$, the seedlings were subcultivated in MS growth medium containing $2 \%$ of sucrose, $0.7 \%$ of agar, and the following concentrations of SA (molecular weight: $138.12 \mathrm{~g} \cdot \mathrm{mol}^{-1}$ ): 0, 50, 100, 200, 300, 400, 500 , and $1000 \mu \mathrm{mol} \cdot \mathrm{L}^{-1}$. The substance was dissolved in a $70 \%$ ethanol solution before being added to the MS medium, whose $\mathrm{pH}$ was adjusted to 5.7.

The treatments were distributed into a completely randomized experimental design. Each treatment corresponded to four replications containing 12 seedlings each, totaling 768 seedlings.

After $210 \mathrm{~d}$ of growth of the seedlings inoculated in the treatments, that is, $300 \mathrm{~d}$ after sowing, the following evaluations were performed in the studied orchids: number of leaves, by counting each fully developed leaf primordium; shoot height, whose reading starting point was set as $2 \mathrm{~cm}$ above the stem base, using a digital caliper (Starrett 7272001; L. S. Starrett Co., Athol, MA); number of roots, by counting the number of roots longer than $2 \mathrm{~mm}$; length of the longest root, using a digital caliper (Starrett 727-2001; L. S. Starrett Co.); leaf area, in $\mathrm{cm}^{2}$, obtained from all the leaves of the plants using a digital area meter (LI-COR L1-3000; LI-COR Biosciences, Lincoln, NE); shoot and root dry weight (the plant material was placed in a forced air oven at $65 \pm 5^{\circ} \mathrm{C}$ during $96 \mathrm{~h}$, and the resulting material was weighed in a $0.001 \mathrm{~g}$ precision Shimadzu analytical balance); and electrolyte leakage (Dionisio-Sese and Tobita, 1998).

All the collected data were submitted to analysis of variance with the F-test and, in case of significance, polynomial regression analyses were performed using the statistics program AgroEstat (Barbosa and Maldonado, 2014).

\section{Results}

Effect of SA on electrolyte leakage. Electrolyte leakage was affected by the presence of SA. Both orchid species showed a negative quadratic behavior, and the minima were observed at SA concentrations of 275 and $155 \mu \mathrm{mol} \cdot \mathrm{L}^{-1}$ for Cymbidium atropurpureo and Phalaenopsis Golden Peoker, respectively (Fig. 1A).

Effect of SA on plant growth and development. The presence of SA reduced the number of leaves in the plants. The results of both examined species were compatible with a negative linear fitting, and at the SA concentration of $1000 \mu \mathrm{mol} \cdot \mathrm{L}^{-1}$ there was a 

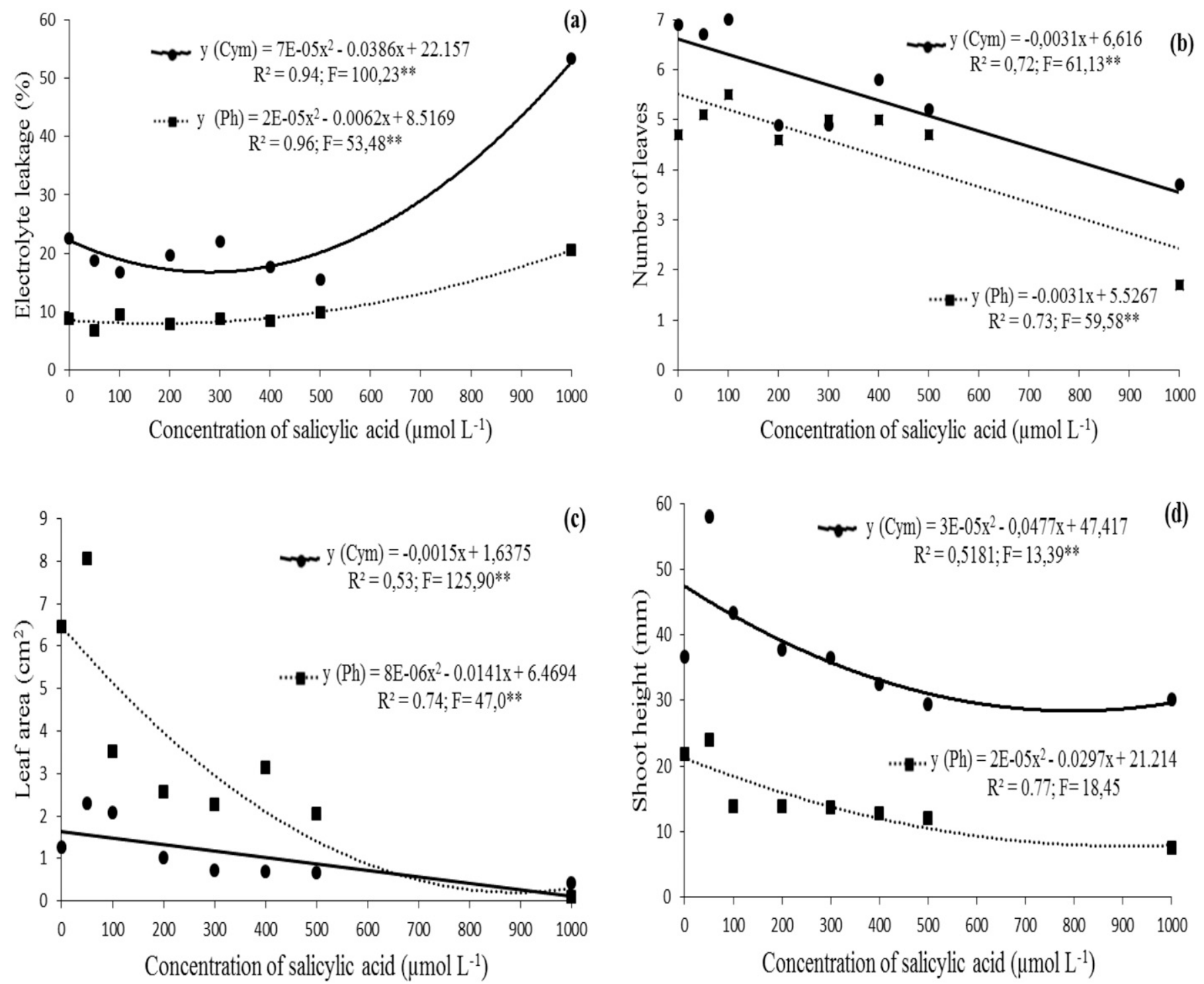

Fig. 1. Electrolyte leakage (A), number of leaves (B), leaf area (C), and shoot height (D) of Cymbidium atropurpureo and Phalaenopsis Golden Peoker as a function of exogenous salicylic acid concentrations after $300 \mathrm{~d}$ of in vitro cultivation. ${ }^{* *} P<0.01$.

reduction of $46 \%$ and $64 \%$ in the number of leaves for Cymbidium atropurpureo and Phalaenopsis Golden Peoker, respectively, in comparison with the number obtained in the control treatment (Fig. 1B).

The leaf area also showed a decrease after the addition of SA to the MS medium. A negative linear fitting was used for the Cymbidium atropurpureo data set, which revealed a reduction in the leaf area of $66 \%$ in comparison with the control treatment at the greatest studied SA dose $\left(1000 \mu \mathrm{mol} \cdot \mathrm{L}^{-1}\right)$. In the case of Phalaenopsis Golden Peoker, a negative quadratic fitting was performed, with a minimum at $881 \mu \mathrm{mol} \cdot \mathrm{L}^{-1}$ of SA (Fig. 1C).

The addition of SA to the MS medium interfered with the shoot height. Data from both species were fitted with a negative quadratic model, with minima at 795 and $742 \mu \mathrm{mol} \cdot \mathrm{L}^{-1} \mathrm{SA}$ for Cymbidium atropurpureo and Phalaenopsis Golden Poker, respectively (Fig. 1D).

The presence of SA in the MS medium impacted on the development of the root system negatively. A negative linear fitting was performed for both species, and a SA concentration of $1000 \mu \mathrm{mol} \cdot \mathrm{L}^{-1}$ caused a reduction in the number of roots of $74 \%$ and $88 \%$ for Cymbidium atropurpureo and Phalaenopsis Golden Peoker, respectively, in comparison with the results for the control treatment (Fig. 2A). Similarly, the root length decreased after the contact with SA. A negative linear fitting was used for Phalaenopsis Golden Peoker, and a reduction of $59 \%$ in the root length was observed in comparison with the value for control plants (Fig. 2B). For Cymbidium atropurpureo, a quadratic model was used to fit the data set, and a minimum was observed at an SA concentration of $623 \mu \mathrm{mol} \cdot \mathrm{L}^{-1}$ (Fig. 2B).

Regarding the root dry weight, it was found that Phalaenopsis Golden Peoker showed a linear decrease in this parameter and a weight reduction of $95 \%$ at the maximum studied SA concentration of 1000 $\mu \mathrm{mol} \cdot \mathrm{L}^{-1}$ in comparison with the control treatment. The Cymbidium atropurpureo data set was fitted with a quadratic model, with a minimum at the SA concentration of $806 \mu \mathrm{mol} \cdot \mathrm{L}^{-1}$ (Fig. 2C).

SA also interfered with the shoot dry weight in both orchid species. Quadratic models were fitted to the collected data, with minima at SA concentrations of 665 and 933 $\mu \mathrm{mol} \cdot \mathrm{L}^{-1}$ for Cymbidium atropurpureo and Phalaenopsis Golden Peoker, respectively (Fig. 2D).

Overall, Phalaenopsis Golden Peoker presented more biological losses caused by the increase in the SA concentration than Cymbidium atropurpureo (Fig. 3).

\section{Discussion}

Electrolyte leakage. The increase in electrolyte leakage in Cymbidium atropurpureo and Phalaenopsis Golden Peoker occurred as a consequence of excess SA, which may have caused changes in several metabolic reactions of the plants, including a potential oxidative stress, partially through the 

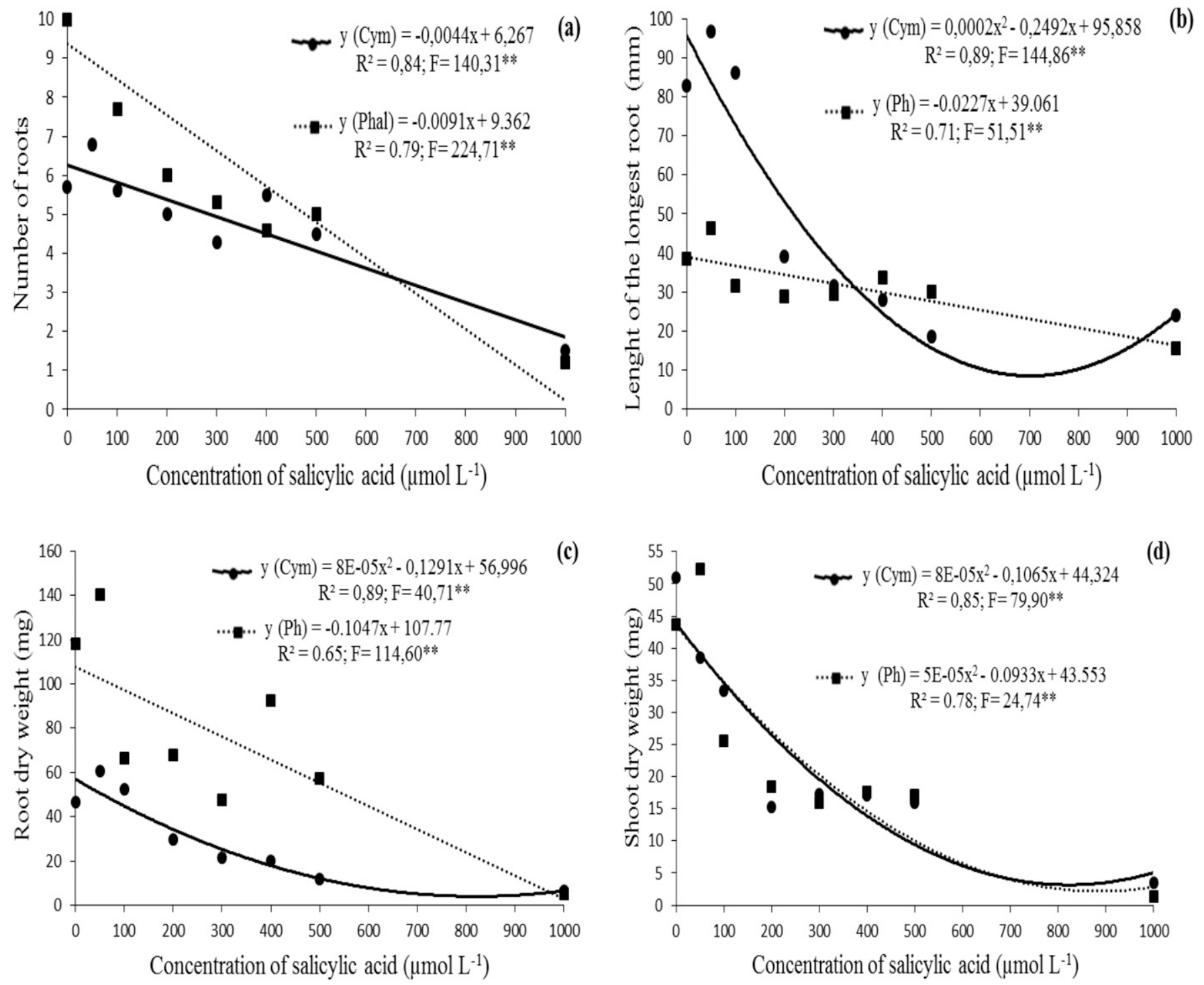

Fig. 2. Number of roots (A), length of the longest root (B), root dry weight (C), and shoot dry weight (D) of Cymbidium atropurpureo and Phalaenopsis Golden Peoker as a function of exogenous salicylic acid concentrations after $300 \mathrm{~d}$ of in vitro cultivation. ${ }^{* *} P<0.01$.

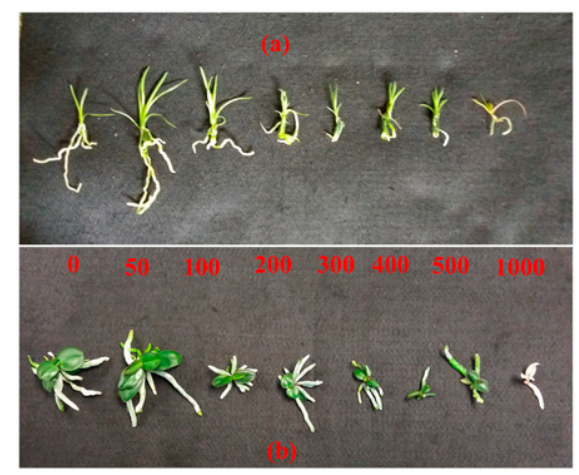

Fig. 3. Seedlings of Cymbidium atropurpureo (A) and Phalaenopsis Golden Peoker (B) after treatment with increasing exogenous salicylic acid concentrations $(0,50,100,200,300,400,500$, and $1000 \mu \mathrm{mol} \cdot \mathrm{L}^{-1}$ ) after $300 \mathrm{~d}$ of in vitro cultivation.

accumulation of hydrogen peroxide (Horváth et al., 2007).

Growth and development. High concentrations of SA in the MS medium impaired the growth and development of Cymbidium atropurpureo and Phalaenopsis Golden Peoker. The substance caused levels of oxidative stress that may have been too extreme for the plants to overcome, as reported by Chen et al. (1993), whose study demonstrated that the SA inhibited the enzyme activity of catalase and induced an increase in the concentration of hydrogen peroxide.

Rao et al. (1997) verified that the treatment with SA led to lipid peroxidation, oxidative damage to proteins, and formation of chlorophyll and carotene isomers in Arabidopsis thalina plants. These alterations can be partially attributed to the inactivation of catalase and ascorbate peroxidase, both from the peroxidase enzyme family, resulting in a lower growth of orchids, which is a phytotoxicity symptom of SA.

\section{Conclusions}

The addition of SA to the MS growth medium at concentrations greater than $50 \mu \mathrm{mol} \cdot \mathrm{L}^{-1}$ induces cellular electrolyte leakage and decreases the in vitro growth of Cymbidium atropurpureo and Phalaenopsis Golden Peoker seedlings. The former proved more tolerant of SA than the latter.

\section{Literature Cited}

Barbosa, J.C. and J.R.W. Maldonado. 2014. AgroEstat-System for statistical analysis of agronomic trials, version 1.1.0.711. School of Agricultural and Veterinary Sciences. São Paulo State University, Jaboticabal, Brazil.

Caldas, L.S., P. Haridasan, and M.E. Ferreira. 1998. Meios nutritivos, p. 87-132. In: A.C. Torres, L.S. Caldas, and J.A. Buso (eds.). Cultura de tecidos e transformação genética de plantas. Brasília: Embrapa-SPI \& EmbrapaCNPH, Brazil.

Chen, Z., H. Silva, and D.F. Klessig. 1993. Active oxygen species in the induction of plant systemic acquired resistance by salicylic acid. Science 262:1883-1886.

Costa, M.A.P.C., M.J. Pereira, M.A. Rocha, D.S Hamsen, R.M.O. Alves, E.H. Souza, and F.R. Garcia. 2009. Micropropagação de orquídeas, p. 351-370. In: T.G. Junghans and A.S. Souza 
(eds.). Aspectos práticos da micropropagação de plantas. Embrapa MFT, Cruz das Almas, Brazil.

Dionisio-Sese, M.L. and S. Tobita. 1998. Antioxidant responses of rice seedlings to salinity stress. Plant Sci. 135:1-9.

El-Housini, E.A., M.A. Ahmed, M.S. Hassanein, and M.M. Tawfik. 2014. Effect of salicylic acid on growth and quality of stevia (Stevia rebaudiana bert.) under salt stress. American-Eurasian J. Agr. \& Environ. Sci. 14:275-281.
Horváth, E., G. Szalai, and T. Janda. 2007. Induction of abiotic stress tolerance by salicylic acid signaling. J. Plant Growth Regul. 26:290 300 .

Martín-Mex, R., E. Villanueva-Couoh, T. HerreraCampos, and A. Larqué-Saavedra. 2005. Positive effect of salicylates on the flowering of African violet. Scientia Hort. 103:499502.

Murashige, T. and F. Skoog. 1962. A revised medium for a rapid growth and bio assays with tobacco tissue cultures. Physiol. Plant. 15:473497.

Rao, M.V., G. Paliyath, D.P. Ormrod, D.P. Murr, and C.B. Watkins. 1997. Influence of salicylic acid on $\mathrm{H}_{2} \mathrm{O}_{2}$ production, oxidative stress, and $\mathrm{H}_{2} \mathrm{O}_{2}$-metabolizing enzymes. Plant Physiol. 115: 137-149.

Yuan, Z., G. Cong, and J. Zhang. 2014. Effects of exogenous salicylic acid on polysaccharides production of Dendrobium officinale. S. Afr. J. Bot. 95:78-84. 